\title{
Inflow Forecast of Iranamadu Reservoir, Sri Lanka, under Projected Climate Scenarios Using Artificial Neural Networks
}

\author{
Chamaka Karunanayake ${ }^{D}$, Miyuru B. Gunathilake ${ }^{D}$, and Upaka Rathnayake \\ Department of Civil Engineering, Faculty of Engineering, Sri Lanka Institute of Information Technology, Malabe, Sri Lanka \\ Correspondence should be addressed to Upaka Rathnayake; upakasanjeewa@gmail.com
}

Received 10 September 2020; Revised 12 November 2020; Accepted 16 November 2020; Published 7 December 2020

Academic Editor: Wan Hanna Melini

Copyright (C) 2020 Chamaka Karunanayake et al. This is an open access article distributed under the Creative Commons Attribution License, which permits unrestricted use, distribution, and reproduction in any medium, provided the original work is properly cited.

\begin{abstract}
Prediction of water resources for future years takes much attention from the water resources planners and relevant authorities. However, traditional computational models like hydrologic models need many data about the catchment itself. Sometimes these important data on catchments are not available due to many reasons. Therefore, artificial neural networks (ANNs) are useful soft computing tools in predicting real-world scenarios, such as forecasting future water availability from a catchment, in the absence of intensive data, which are required for modeling practices in the context of hydrology. These ANNs are capable of building relationships to nonlinear real-world problems using available data and then to use that built relationship to forecast future needs. Even though Sri Lanka has an extensive usage of water resources for many activities, including drinking water supply, irrigation, hydropower development, navigation, and many other recreational purposes, forecasting studies for water resources are not being carried out. Therefore, there is a significant gap in forecasting water availability and water needs in the context of Sri Lanka. Thus, this paper presents an artificial neural network model to forecast the inflows of one of the most important reservoirs in northern Sri Lanka using the upstream catchment's rainfall. Future rainfall data are extracted using regional climate models for the years 2021-2050 and the inflows of the reservoir are forecasted using the validated neural network model. Several training algorithms including Levenberg-Marquardt (LM), BFGS quasi-Newton (BFG), scaled conjugate gradient (SCG) have been used to find the best fitting training algorithm to the prediction process of the inflows against the measured inflows. Results revealed that the LM training algorithm outperforms the other tests algorithm in developing the prediction model. In addition, the forecasted results using the projected climate scenarios clearly showcase the benefit of using the forecasting model in solving future water resource management to avoid or to minimize future water scarcity. Therefore, the validated model can effectively be used for proper planning of the proposed drinking water supply scheme to the nearby urban city, Jaffna in northern Sri Lanka.
\end{abstract}

\section{Introduction}

Water is the livelihood of civilization. The demand for usable water is always high in any community; therefore, this has made many conflicts in the history. Whether they are recorded or not in a reliable way, the history of conflicts for water extends up to the civilization of humans [1-4]. Demand for various water usages made these conflicts more significant. Negotiation among different stakeholders brings different aspects to water usage and they can initiate different issues. For example, some people might argue that the priority should be given to drinking water rather than agriculture. However, farmers might argue that the priority should be given to them as they are living closer to the particular water resources. Therefore, conflicts for water may even happen between communities of the same country.

On the other hand, Sri Lanka as a country has faced many conflicts due to water over the history [5-8], even though the country has many water resources. It is a waterrich country. It has managed its water resources well over the past. However, there are several incidents where the conflicts are brought to the society by various stakeholders. Water resources management in the Iranamadu reservoir, which is in the northern part of Sri Lanka, is one of such cases to showcase the water conflicts in Sri Lanka. 
At the same time, climate change and climate variabilities have done many adverse impacts to the water resources not only to Sri Lanka but also all over the world. Some countries, like Ethiopia, Somalia, Djibouti, Eritrea, Kenya, and Slovakia, have experienced arid weather patterns $[9,10]$, while some other countries, like the United Kingdom, Sri Lanka, Lithuania, and Myanmar, have experienced intensified precipitation events $[11,12]$. The adverse impacts of these extreme climate events have influenced water supply systems [13], sewer systems [14], agriculture [15], hydropower development [16], and transportation [17]. However, triggering natural disasters like landslides, floods, and torrential winds brings more weight to the problem.

In addition, the impact of climate change has been witnessed in many other multiple sectors. For example, significantly higher temperatures, which were the cause of heat waves, have damaged the ecosystems, human health, and agriculture in European regions [18-20]. In addition, it was showcased that increasing atmospheric temperatures has significantly decreased the agricultural productivity in Pakistan [21]. On the other hand, freezing temperatures due to climate change have damaged the agricultural yield $[22,23]$. Not only the losses in agriculture due to climate change, but also there is plenty of evidence in many other areas for the impact of climate change, including biodiversity, water resources, and hydropower.

Therefore, proper planning and management of water resources is a must for the future world. The projected climatic scenarios can be used to identify the available water resources for future years, and thus, appropriate measures can be preplanned. These measures might not have to be perfect; however, an acceptable accuracy would grab the interest of many stakeholders. Therefore, prediction or forecast of inflows to a reservoir is highly important.

Time series inflow prediction in reservoirs is an important task (probably the most important) in controlling the storage of a reservoir. Thus, it is a necessary activity to manage the water resources for various downstream tasks including drinking water supply, hydropower development, and irrigation. There are several ways of predicting the inflow to the systems starting from simplified tank models [24-27] to unsteady hydrological routing models [28-32]. Literature shows these approaches are clustered into empirical, conceptual, physical, and data-driven models [33-36]. However, usage of artificial neural networks has introduced a reasonably new approach (compared to the traditional computational models) in predicting catchment inflows without using many physical catchment data.

Forecasting techniques are varied from one catchment to another catchment depending on the available catchment characteristics. In addition to that, data availability plays a major role in the accuracy of the forecasting models $[37,38]$. Furthermore, different computational models have different modeling accuracies in the forecasting process.

Some researchers have combined genetic algorithms and ANN to predict the inflows to reservoirs [39]. Results from Sedki et al. [39] have shown that the hybrid models combining genetic algorithms to ANN outperform the traditional ANNs. However, a well-trained ANN model can still be a useful tool to predict the inflow to a reservoir at low computational cost. In addition, ANNs do not need stationary variables to be stationary and normally distributed compared to classical stochastic modeling [40, 41]. Furthermore, ANNs are comparably stable for the various noises in the measured data [42]. Also, ANNs are capable of modeling complex and nonlinear hydrological processes [43]; having a self-adjusting ability to the data [44], needing a limited knowledge of the hydrological process [45], easy integration to other models [43], and less demand in computational cost are few other advantages of ANNs in hydrological processes.

Nevertheless, inflow predictions using ANNs have some disadvantages too. Nonstationary data have some impacts to the predictions $[46,47]$. The extreme events in meteorology may not be captured in the predictions. Therefore, the inflow predictions may misguide the planners and authorities. In addition, the seasonal effects of rainfall can adversely impact the quality of the predictions [48].

However, despite several disadvantages, literature gives many examples of inflow prediction using ANNs [49-54] due to their advantages. Many researchers have used different types of algorithms in predicting inflows using ANNs. For example, Kişi [55] has used four different algorithms, including backpropagation, conjugate gradient, cascade correlation, and Levenberg-Marquardt in their streamflow predictions. However, the usage of ANN to predict inflows in Sri Lanka is quite new. Only a handful of number of research has been done to Sri Lanka in the same manner [56, 57]. Basnayake et al. [56] have developed a model to forecast the monthly inflow to one of the major reservoirs in the wet zone of Sri Lanka. They have used nonlinear autoregressive with exogenous input (NARXANN) neural network; however, they have not presented their model with the projected climatic cases for future years. Apart from the studies by Basnayake et al. [56, 57], the authors could not find related research in the context of Sri Lanka. In addition, the importance of such study is visible, when there are conflicts in the water usages in the dry zone of the country.

Therefore, it is timely important to conduct a hydrological catchment analysis to predict the inflow of the Iranamadu reservoir and thus to investigate the cultivation capacity of the Iranamadu reservoir in the upcoming development projects under the ongoing climate change scenarios. Thus, this paper presents the soft computing techniques in finding the relationships between the catchment's rainfall and the inflow to the Iranamadu reservoir. The conventional method of flow calculation, hydrological catchment modeling, was not conducted here due to two important reasons: unavailability of various data and complexity of the real-world hydrological models in the absence of various required data, including a dense network of rain gauges, timely measured streamflows, soil infiltration, and evaporation. The obtained relationship was then used to forecast the Iranamadu inflow for the years 2021-2050 from the projected climate scenarios. The future climate data were extracted from regional climate models using the Coordinated Regional Downscaling Experiment (CORDEX). 
The results presented here reveal the importance of such a study in the context of data unavailability and the usage of the developed model in future water management in the Iranamadu reservoir.

\section{Study Area and Its Water Scarcity Issues}

Iranamadu reservoir is the largest reservoir in northern Sri Lanka and can be considered one of the most important reservoirs in that area. The reservoir is nutrified by the Kanakarayan Aru, a $86 \mathrm{~km}$ long river, which starts from Semamadu Kulam in Vavuniya district. As it was already stated, conflicts have aroused in the area due to the water resources of this reservoir. The irrigational water supply from the reservoir is comparably significant as many other reservoirs in Sri Lanka. The reservoir caters around $8000-10000$ ha of paddy fields in the region.

Sri Lanka practices two cultivation seasons, namely, Maha and Yala seasons. Maha is the major cultivating season whereas Yala is the minor season. Maha season starts in September and lasts until March of the next year. However, Yala season starts in May and ends in August. The season itself is treated to be a minor season due to low irrigational water availability during the drier months.

Figure 1 shows the cultivated land areas and the respective paddy harvests over the years for Maha (see Figure 1(a)) and Yala (see Figure 1(b)) seasons (Maha and Yala are the two major agricultural seasons of the country). Even though there is no connectivity from one year to another, dashed lines are used to showcase the variation clearly. There were no cultivations during the 2008 to 2009 years due to intensified war activities in the region. However, since 2009, the area was well cultivated. This is an advantage; which Sri Lanka is enjoying because of the end of the war conflict. The figures reveal a greater correlation between the cultivated land areas and paddy harvest. However, there are drops in both cultivated land areas and harvest (for example: in 2012 and 2016 in Maha season and in 2014, 2016, 2017, and 2018 in Yala season). The main reason for this was the unavailability of water resources in the Iranamadu reservoir due to the severe drought conditions in the area.

Iranamadu tank was the first new tank to be built by the Department of Irrigation, Sri Lanka, other than restoration of ancient irrigational tanks [59]. This tank with a catchment area of $588 \mathrm{~km}^{2}$ was built damming two low-lying swamps of the Kanakarayan Aru. The construction of Iranamadu tank with a capacity of 49 million cubic meters (MCM) was initiated in 1902 by the Department of Irrigation and the tank dam was raised to hold a capacity of 88 MCM in 1951. The dam was further raised by 2 feet in 1954 and that increased the capacity to $101 \mathrm{MCM}$. The dam was raised from time to time and now it is at the height of $34 \mathrm{~m}$ (from mean sea level (MSL)). The tank can now hold water up to 148 MCM [60]. It is clearly evident the importance of the tank to Kilinochchi area from these time-to-time dam height rises. The water is mainly used for irrigational purposes and the demand for the irrigational water has increased with time (see Figure 1).

\section{Future Climate Data Extraction}

Regional climate models (RCMs) are numerical prediction models, which use the boundary conditions of global climate models (GCMs). RCMs are developed in the interests of localized regions rather than globally. There have been increasing trends in using regional climate models (RCMs) for climate change impact studies due to the fine resolution in between 12 and $50 \mathrm{~km}$ when compared to coarse resolution in between 100 and $250 \mathrm{~km}$ of global climate models (GCMs). Yet, these RCMs inherit significant biases due to imperfect conceptualization, internal climatic variability, discretization, and spatial averaging within grid cells [61-63]. Bias correction methods including linear scaling method, quantile mapping, and local intensity scaling can be used to reduce the biases in climatic datasets [62]. The bias correction process is usually carried out because of limited spatial resolution and simplified physics of the models. In addition, the physics of the world is yet to be revealed, and thus, the models usually produced some biased future climate data.

ACCESS_CCAM, MPI_ESM_CCAM, CNRM_CCAM, and REMO2009 are four RCMs, which were developed by the Commonwealth Scientific and Industrial Research Organization (CSIRO) of spatial resolution $0.5^{\circ} \times 0.5^{\circ}[64,65]$ from Coordinated Regional Downscaling Experiment (CORDEX). The driving GCMs of these RCMs are ACCESS 1.0, MPI_ESM_LR, CNRM_CM5, and ECHAM-4 GCM $[66,67]$, respectively. Climatic data of CORDEX are available through https://www.cordex.org/. These RCMs are widely used for climate studies. The climatic data for the years 1976-2100 are available in RCMs, comprising a historical period in between 1976 and 2005 and future period between 2006 and 2100 .

\section{Forecasting Model Development}

Rainfall data for three rain gauging stations placed inside the catchment area of Iranamadu reservoir (naming Olumadu, Iranamadu, and Mankulam) were obtained from the Department of Irrigation, Sri Lanka. In addition, the inflows to the reservoir were collected from the same department for 30 years from 1959 to 1989 . Most of the rainfall data are missing after 1989 due to various reasons, mainly the war in this area until 2009. In addition, the Mankulam rain gauge has not functioned well in recent years. Therefore, the authors have to rely on the monthly rainfall data and reservoir inflow data for the period of 1959 to 1989. During this period, the missing data percentage is less than $10 \%$ (Olumadu-0\%, Iranamadu-6.9\%, and Mankulam-1.9\%). The annual variations of the rainfall in three gauges are given in Figure 2. As they were expected, zigzag variations can be observed in all three annual rainfall variations. The annual rainfalls were interconnected along the time axis to show the temporal variations, even though the annual rainfalls are not interconnected.

Inflow to the Iranamadu reservoir from Kanakarayan Aru based on the rainfall of three rain gauges was modeled 


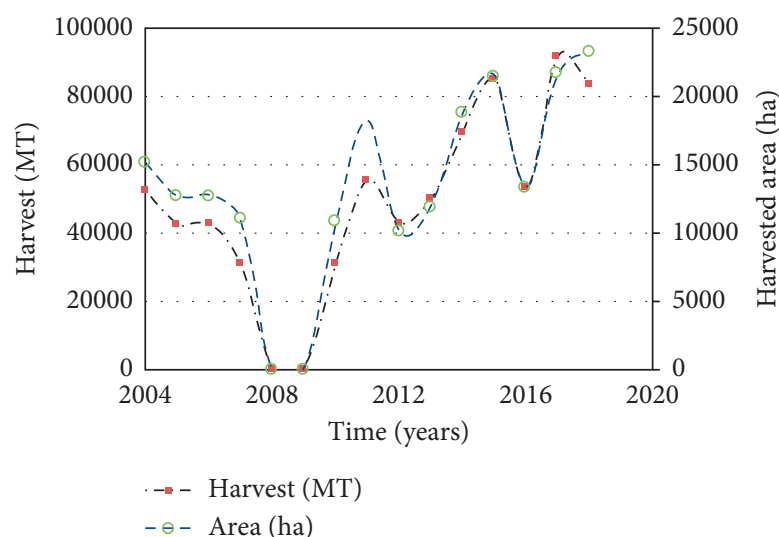

(a)

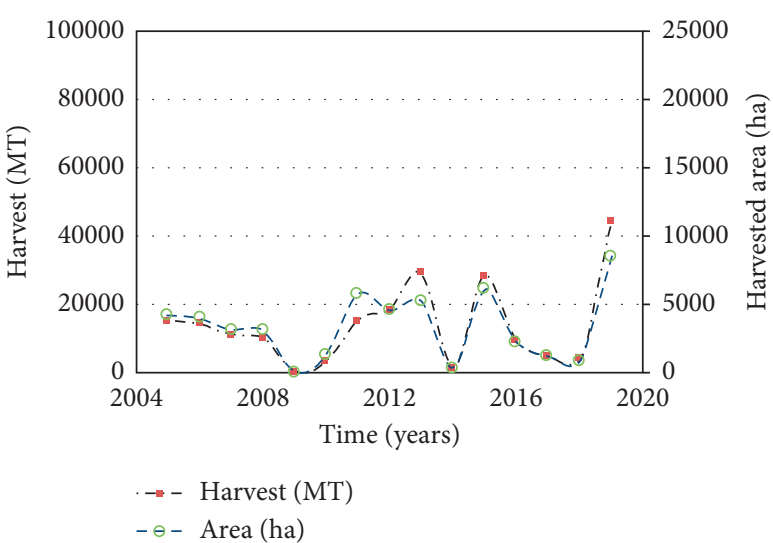

(b)

FIgURE 1: Paddy harvest with respect to the cultivated area in Kilinochchi district (data source: [58]). (a) For Maha season and (b) for Yala season.

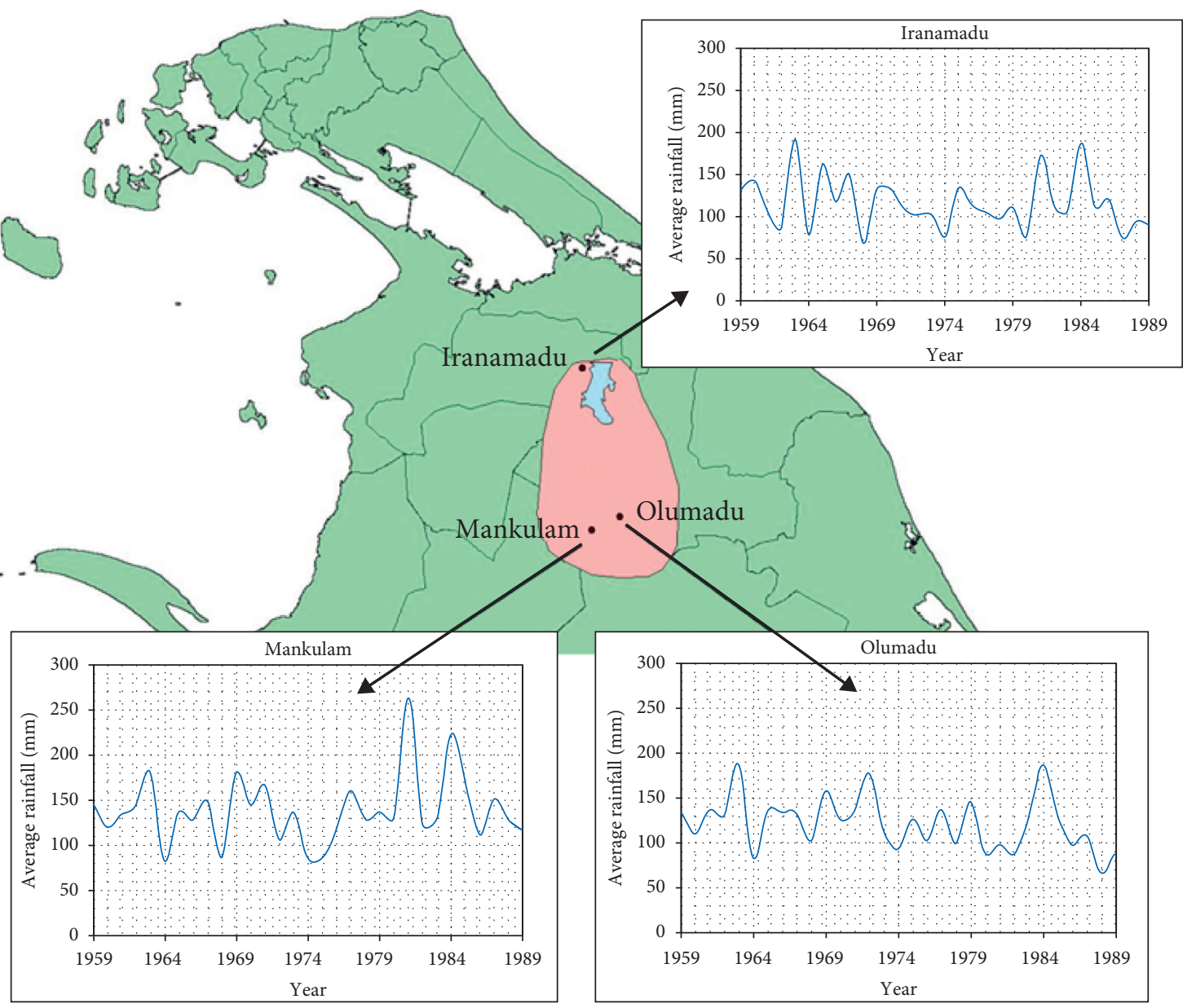

FIGURE 2: Rain gauges and rainfall variation over the years.

using catchment's rainfall in the ANN environment. The relationship is given in the following equation:

$$
\text { Inflow }=\phi\left(\text { Rain } \text { fall }_{i}\right) \text {, }
$$

where $\phi$ is the nonlinear function in between inflow and rainfall and $i$ represents the rain gauges. $70 \%$ of the data was fed to ANN architecture to train the neural network, whereas $15 \%$ was used to validate the trained neural network and 
another $15 \%$ to test the validated neural network. The feedforward neural network (FFNN) was in this study. FFNN works in one direction (forward) from inputs to outcome through the hidden nodes. There is no feedback in the FFNN and it is the simplest form of ANNs. However, they can still be effectively used to model complex scenarios.

The developed ANN model was trained using seven algorithms, namely, BFGS quasi-Newton (BFG), Fletcher-Reeves conjugate gradient algorithm (CGF), scaled conjugate gradient (SCG), Polak-Ribiére conjugate gradient (CGP), conjugate gradient with Powell/Beale restarts (CGB), Levenberg-Marquardt (LM), and resilient backpropagation (RP) algorithms. These algorithms are widely used in realworld problems [68-70]. The problem was tested on these seven ANN algorithms to check their suitability and stability in the specified application. More information on these algorithms can be found in Perera et al. [71].

The trained ANN model was saved for the future forecasting process. The ANN prediction process was validated using the data from 1999 to 2000 . This process was carried out to revalidate the developed model using available rainfall data for a future period from the model development. The monthly rainfall data of the stations Iranamadu and Olumadu were readily available whereas the data for Mankulam station were not available. In addition, Iranamadu inflow data were available for this period. Therefore, 1999-2000 two years were selected to do the prediction validation of the ANN model. The missing rainfall days were filled with gridded precipitation datasets from APHRODITE's (Asian Precipitation Highly Resolved Observational Data Integration Towards Evaluation of Water Resources) precipitation dataset [72, 73]. The precipitation data related to the location of Mankulam (9.13700N, 80.44520E) were extracted from APHRODITE's dataset (available at http://aphrodite.st.hirosaki-u.ac.jp/) using ARCGIS (version 10.4). The validity of the APHRODITE dataset for Mankulam was checked before the application. The data from APHRODITE and the observed data were compared for 10 years (1979-1989). The resulting Pearson correlation coefficient $(0.7916)$ obtained was greater than 0.75, and hence, the dataset from APHRODITE was used to extract monthly rainfall data of Mankulam station for the years 1999 and 2000.

The monthly rainfall data for 1999-2000 were fed to the developed ANN model and derived the streamflows to the corresponding months as the predicted streamflows. These predicted streamflows were then compared against the measured streamflows for the 1999-2000 time.

After the prediction validation, rainfall data for 30 years from 2020 to 2050 were extracted from four regional climate models (namely, ACCESS_CCAM, MPI_ESM_CCAM, CNRM_CCAM, and REMO2009) for Iranamadu, Olumadu, and Mankulam. Two Representative Concentration Pathways (RCP4.5 and RCP8.5) were used for rainfall data extraction. The RCPs are greenhouse gas emission concentration trajectories adopted by the IPCC [74]. These two RCPs were selected based on their emission scenarios. RCP4.5 is a medium emission scenario and RCP8.5 high emission scenario. More details on RCP scenarios can be found in Van Vuuren et al. [75].
Linear scaling method (LS) [76] was used to remove biases in the rainfall data. The linear scaling approach assumes that the correction algorithm and parametrization of historical climate will remain stationary for future climatic conditions. Previous studies demonstrate that LS approach performs well for coarse temporal scale analysis as more complicated methods such as quantile mapping, delta change, and power transformation [77, 78]. Mathematical formulations for bias correction in precipitation are given in equations (2) and (3). The linear scaling correction was applied at all stations individually.

$$
\begin{aligned}
& P_{\mathrm{his}}^{*}(d)=P_{\mathrm{his}}(d) \times \frac{\mu_{m}\left(P_{\mathrm{obs}}(d)\right)}{\mu_{m}\left(P_{\mathrm{his}}(d)\right)}, \\
& P_{\mathrm{sim}}^{*}(d)=P_{\mathrm{sim}}(d) \times \frac{\mu_{m}\left(P_{\mathrm{obs}}(d)\right)}{\mu_{m}\left(P_{\mathrm{his}}(d)\right)},
\end{aligned}
$$

where ${ }^{*}$, his, obs, sim, $P$, and $d$ stand for bias-corrected data, raw RCM hindcast, observed data, raw RCM-corrected data, precipitation, and daily, respectively. $\mu_{m}$ is the long-term monthly mean of the precipitation data. The corrected rainfall data were then fed to the saved ANN to predict the future inflows to the Iranamadu reservoir.

\section{Results and Discussion}

Table 1 presents the coefficient of correlation and performances of each training algorithms in the ANN analyses. It can be clearly observed that all algorithms have performed well in the context of correlation coefficients. They are almost 1 for validation and more than 0.8 for all other cases. These values are acceptable in the time-dependent highly nonlinear climate analyses [79-82]. However, out of them, LM algorithm has outperformed other training algorithms in the computational performance (highlighted in grey). It has given better results in less computational time (8 epochs) and lowest mean squared error $(M S E=6.14)$. Therefore, LM training algorithm was selected for the prediction analyses.

Figure 3 gives the illustrations of the correlation coefficients of LM algorithm in training, validation, test, and all cases. It can be understood that the prediction is well validated in the developed ANN architecture. The results are scattered along the $45^{\circ}$ line (ideal match) for all cases. Therefore, this observation validates the procedure, which was used in this analysis.

Figure 4 presents the predicted (from ANN model) inflow to the Iranamadu reservoir against the actual measured inflow for the years 1999-2000. The trend line drawn to the data scatter has a coefficient of determination of 0.954 (which is almost 1). That means the trend line almost gives the real feeling of the data scatter. In addition, the equation to the linear trend line drawn is given in the figure itself. In fact, if the predicted inflow has a perfect match to the measured inflow, the equation of the line should be $\mathbf{y}=\mathbf{x}$ (predicted inflow=measured inflow). However, this is the ideal match. The trend line gives an inclination of 0.826 (which is equal to 39.5 degrees). Therefore, the prediction is slightly lower than the actual measured inflow. In addition, 
TABLE 1: ANN results from different training algorithms.

\begin{tabular}{|c|c|c|c|c|c|c|}
\hline \multirow{2}{*}{ Algorithm } & \multicolumn{4}{|c|}{ Correlation coefficients } & \multicolumn{2}{|c|}{ Performance } \\
\hline & Training & Validation & Test & All & MSE & Epochs \\
\hline BFG & 0.986 & 0.978 & 0.97 & 0.983 & 10.17 & 21 \\
\hline CGF & 0.847 & 0.978 & 0.825 & 0.861 & 47.01 & 15 \\
\hline SCG & 0.98 & 0.988 & 0.981 & 0.981 & 7.41 & 66 \\
\hline CGP & 0.978 & 0.957 & 0.957 & 0.971 & 21.19 & 12 \\
\hline CGB & 0.973 & 0.977 & 0.961 & 0.972 & 13.33 & 17 \\
\hline LM & 0.989 & 0.989 & 0.947 & 0.983 & 6.14 & 8 \\
\hline $\mathrm{RP}$ & 0.977 & 0.97 & 0.947 & 0.971 & 11.52 & 40 \\
\hline
\end{tabular}

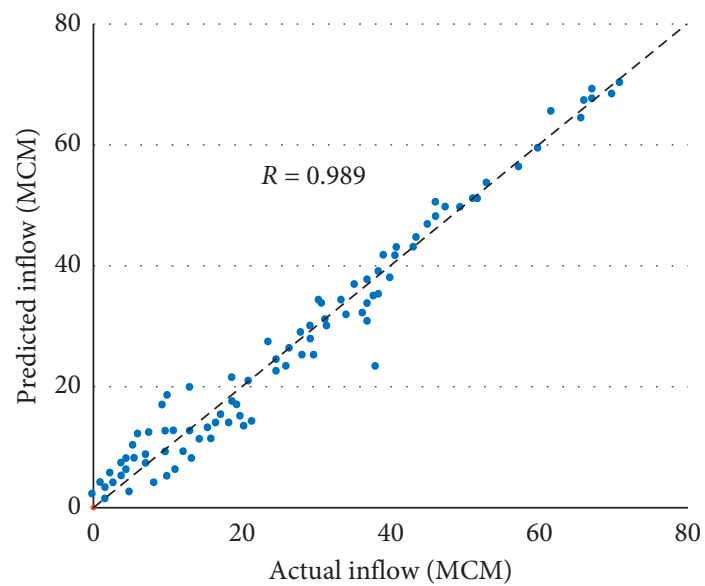

(a)

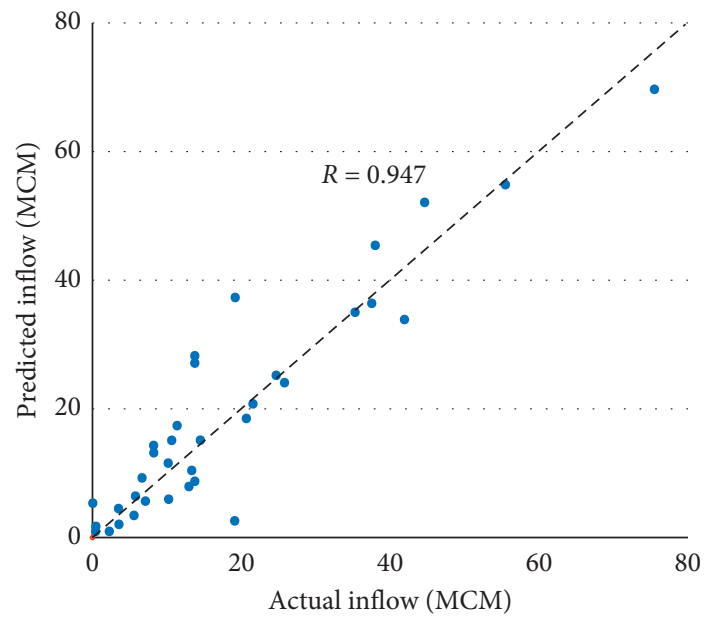

(c)

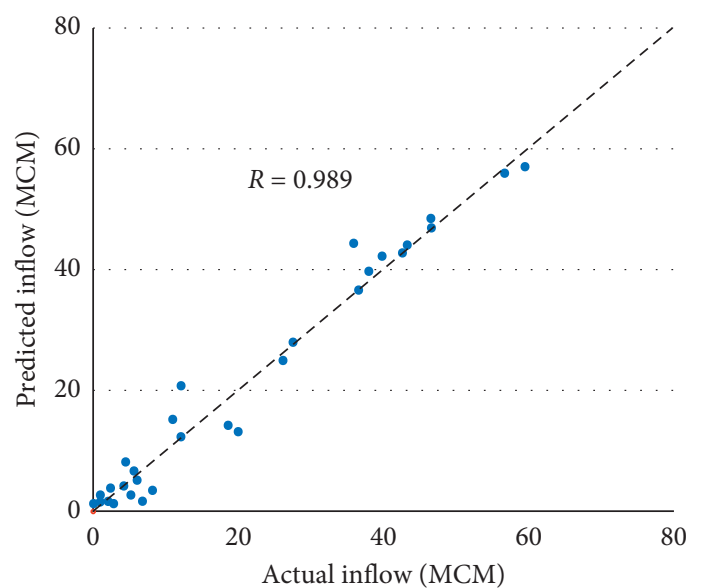

(b)

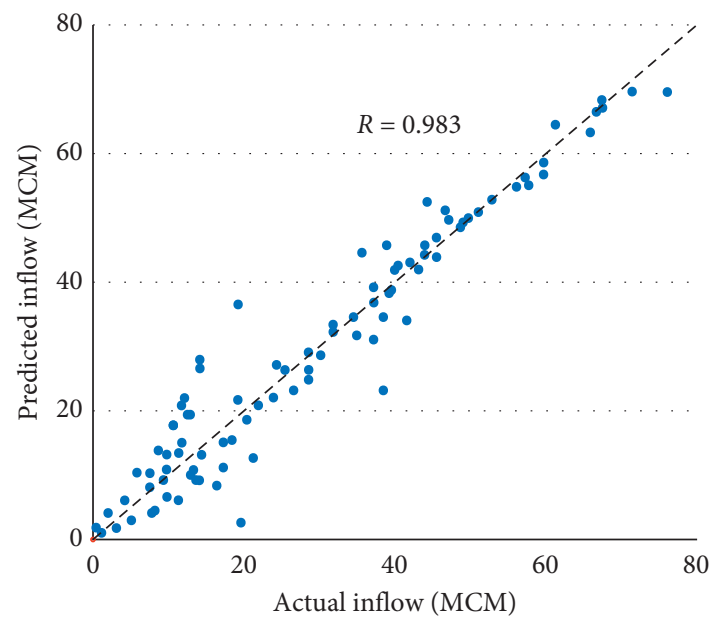

(d)

FIGURE 3: Correlation coefficients for LM algorithm: (a) for training, (b) for validation, (c) for test, and (d) for all (combining training, validation, and testing).

the graph has an MSE of 16.11 MCM. Even though there is a slight deviation, the results show a validation to a greater extent.

The bias-corrected annual rainfalls for three rain gauging stations are given in Figure 5 (Iranamadu (Figure 5(a)), Mankulam (Figure 5(b)), and Olumadu (Figure 5(c))). The figures give the projected rainfall for two RCPs, which were considered in this analysis. The variations are given in dashed lines for a clear understanding of the temporal variations of the rainfall, even though there is no connectivity of rainfall from one year to the next year. As it is expected, annual rainfall variations show a zigzag pattern. Years 2041 and 2045 are two possible extreme years for RCP4.5 scenario. Heavy rainfalls are projected for the year 2041 for all three stations whereas lowest rainfalls are predicted for the year 2045. However, interestingly, RCP8.5 


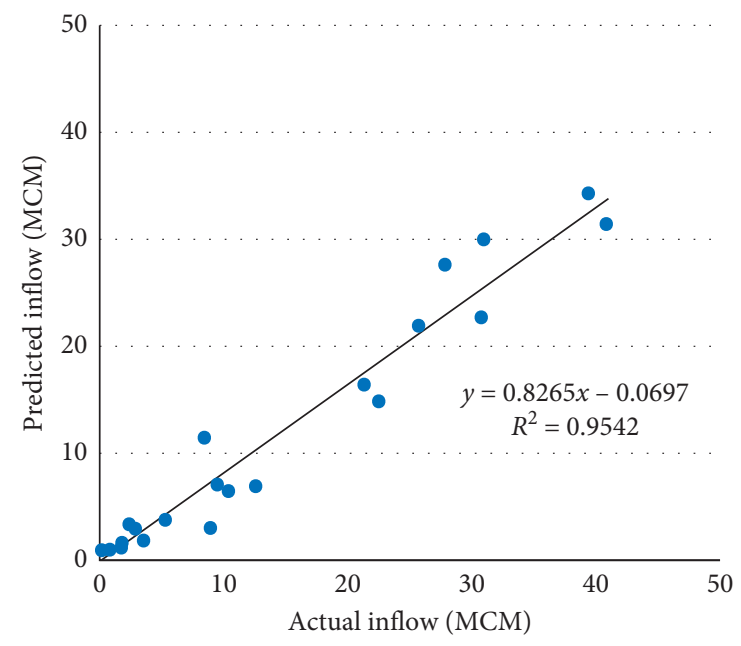

Figure 4: Inflow validations for the years 1999-2000.

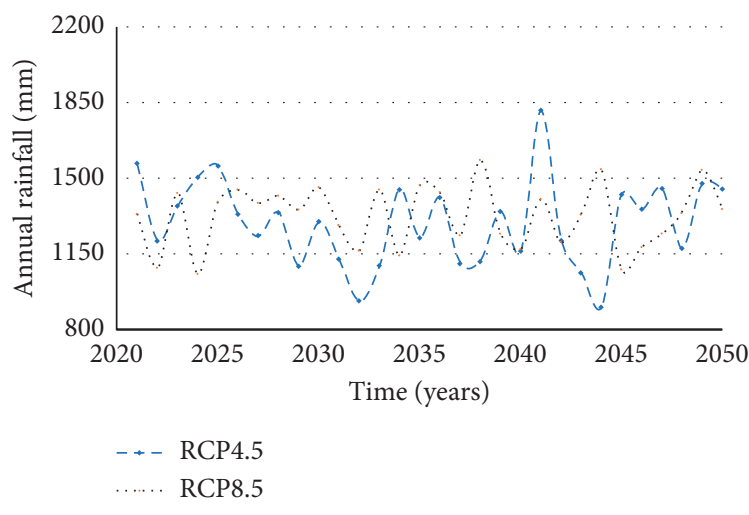

(a)

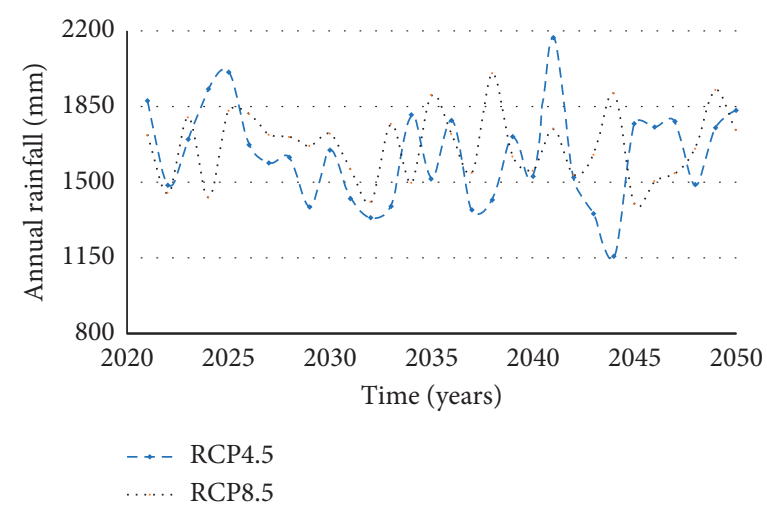

(b)

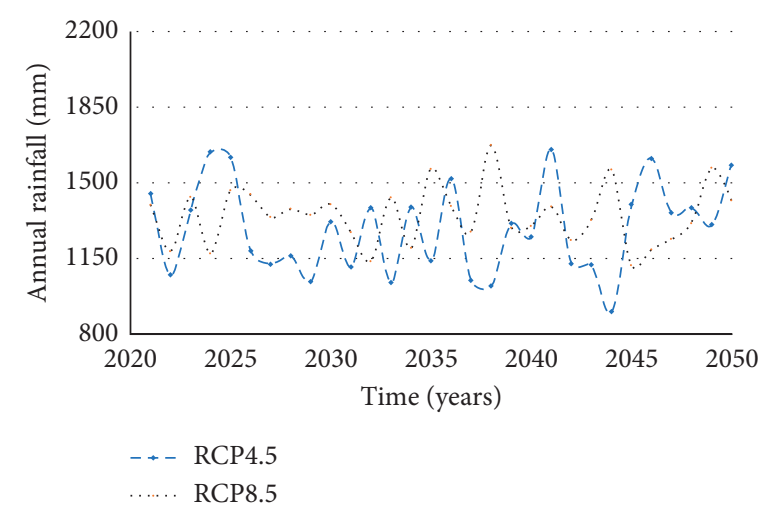

(c)

FIGURE 5: Projected annual rainfall variation from 2021 to 2050: (a) for Iranamadu, (b) for Mankulam, and (c) for Olumadu.

scenario gives a different projection for the year 2045. Instead of the lowered rainfall projections, higher rainfalls can be projected in all three stations. These are projected observations where a detailed research is essential to comment. However, planners can use these projections for their future activities based on the rainfall.

In addition to the annual projections, monthly rainfall projections are also obtained. The projected rainfall for the year 2021 over the months (see Figures 6(a) for RCP4.5 and 6(b) for RCP8.5) are given under the secondary data in the Appendix section. Heavy rainfalls can be expected in the months of October to December in both RCP scenarios. The northern area of Sri Lanka receives its maximum rainfall during the northeastern monsoon, which is practiced from December to February. However, the higher rainfalls are projected in the $2^{\text {nd }}$ intermonsoon period (October to 


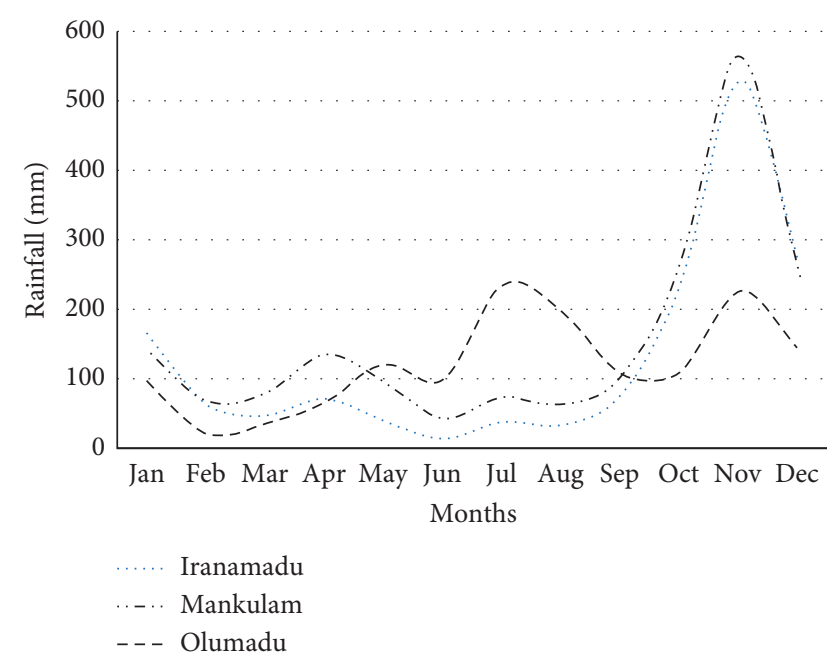

(a)

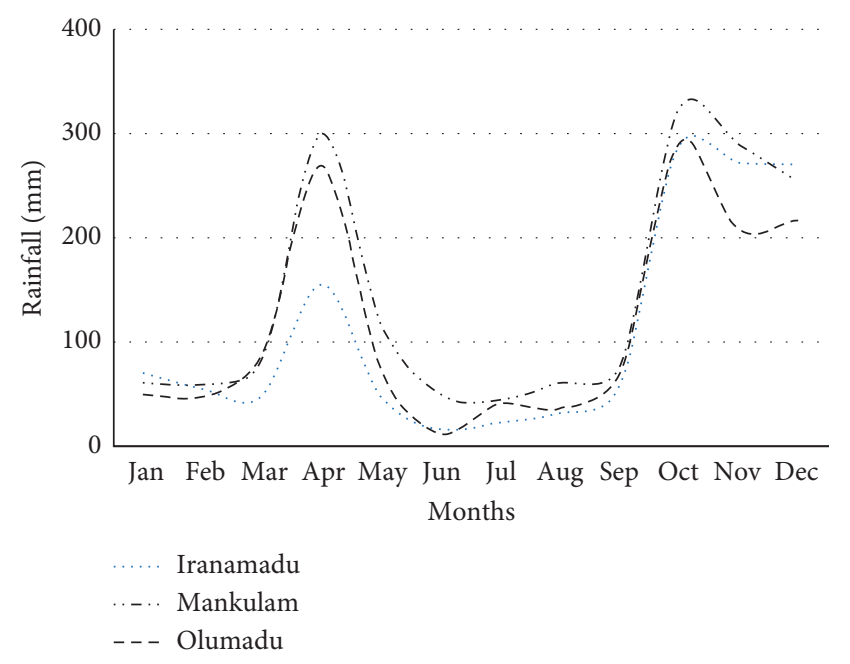

(b)

FIgURE 6: Monthly rainfall variations in the year 2021. (a) For RCP4.5 and (b) for RCP8.5.

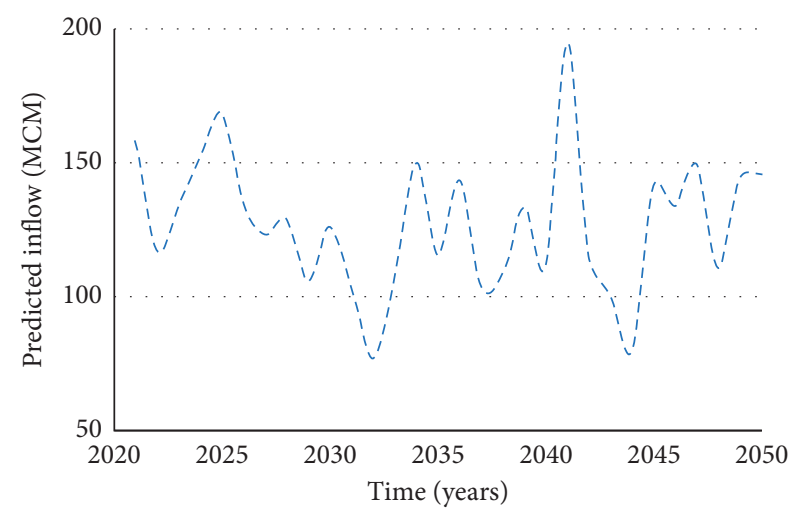

(a)

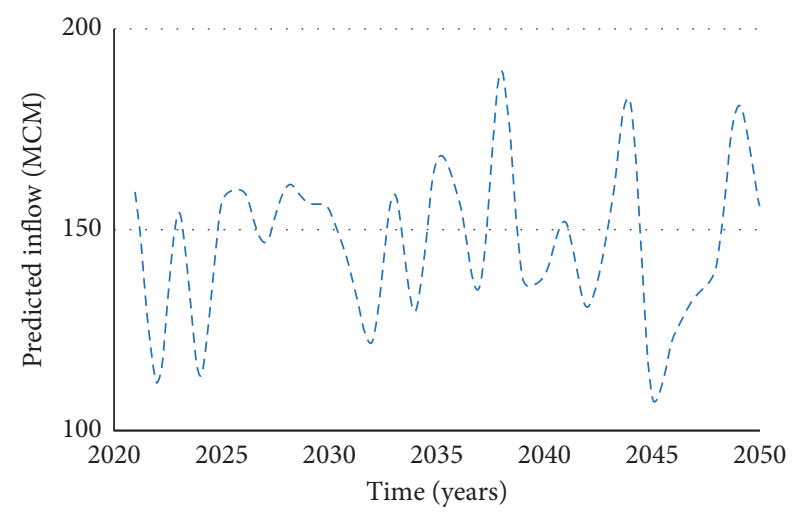

(b)

FIGURE 7: Inflow prediction to the Iranamadu reservoir from 2021 to 2050. (a) For RCP4.5 and (b) for RCP8.5.

November). Therefore, this is interesting as farmers are getting ready for the new cultivation season.

Local farmers usually state that the rainy seasons are shifted in recent years. This is not scientifically proved yet. However, that statement with the observations in monthly variations is to be researched in detail for sound conclusions. Interestingly, RCP8.5 scenario projects another rainfall peak in April for all three stations. This is in the $1^{\text {st }}$ intermonsoon (March to April), where usually a direr period is observed in northern Sri Lanka. Therefore, it would be better to conduct a detailed research along the lines of the impact of climate change on water resources in the Iranamadu area.

The most important finding of this research, inflow to the Iranamadu reservoir forecast, is illustrated in Figure 7 (see Figure 7(a) for RCP4.5 scenario and Figure 7(b) for $R C P 8.5)$. The projected inflows from the years 2021 to 2050 are presented. Annual inflows are not interconnected; however, they were presented by the dashed lines for clarity of the variations. Not only the annual forecasts but also the monthly inflow forecasts are obtained in this research. However, they are not presented here due to space limitations.

Inflow forecasts clearly showcase the importance of future water management in the Iranamadu reservoir. Several peaks and troughs can be visible in the inflow. Peaks can easily lead to flooding in the area due to the noncontoured area. However, the drought seasons would be tough in managing water as there is water scarcity in the drier seasons. Therefore, proper planning is required, and the results of this analysis can be used.

The available statistics show that the average annual inflow to the Iranamadu reservoir between the years 1958 and 2014 is $143 \mathrm{MCM}$. However, the forecasts projected that to be $154 \mathrm{MCM}$ for RCP4.5 and 178 MCM for RCP8.5. Therefore, the average annual inflow (from 2021 to 2050) to the Iranamadu reservoir can be higher compared to that from 1958 to 2014. Nevertheless, as stated, the demand for the water from the Iranamadu reservoir has been increased over the years and projected to increase. 
In addition, there is a proposal to transfer a significant amount of water $\left(27000 \mathrm{~m}^{3} /\right.$ day $)$ from the Iranamadu reservoir to northern city, Jaffna. Therefore, the water management strategies would have to be rearranged in the Iranamadu reservoir to cater to these new demands. If not there may be some conflicts among the farmers and the water distribution planners for the water in the Iranamadu reservoir.

Conflicts may be further increased with the population growth. More agricultural lands would be utilized to cater to the food industry, whereas more drinking water will be required in increasing population. Therefore, these are critical issues to be handled at extremely careful levels.

\section{Conclusions}

Artificial neural network model under the LM algorithm has outperformed all other training algorithms in the inflow prediction model. Therefore, the inflow prediction model from Kanakarayan Aru to the Iranamadu reservoir in northern Sri Lanka is set under the LM training algorithm. The validation process of the inflows from the predicted and measured data reveals the accuracy and robustness of the prediction model. Therefore, the model can be used to forecast the inflows to Iranamadu under any future climate scenarios. The results reveal its applicability only for 2 tested RCPs; however, depending on the requirement, the model can be successfully used. The inflow forecast in the coming 30 years is highly important to the water resources managers to deal with the conflicts among various stakeholders under the water scarcities. Therefore, the forecast can be used in the planning of future arrangements to develop the water distribution network to the Jaffna city. In addition, the water resources in this dry area can be utilized in a sustainable manner among various stakeholders including farmers in the area. Proper crop management can be introduced to the farmers based on the future inflow availability. Therefore, the results from this research are highly important to the water resources managers and planners in the provincial council and the local authorities.

\section{Data Availability}

The climatic data and the analysis data are available from the corresponding author upon request.

\section{Disclosure}

The research was carried out in the Sri Lanka Institute of Information Technology environment.

\section{Conflicts of Interest}

The authors declare no conflicts of interest.

\section{Acknowledgments}

The authors would like to acknowledge and appreciate Dr. Arulanantham Anburuvel, Senior Lecturer in Faculty of Engineering, University of Jaffna, Sri Lanka, and Eng.
N. Suthakaran, the Deputy Director of the Department of Irrigation, Kilinochchi, Sri Lanka, for their effort in obtaining the rainfall and inflow data for the Iranamadu reservoir. This research received no external funding.

\section{References}

[1] L. J. Del Giacco, R. Drusiani, L. Lucentini, and S. Murtas, "Water as a weapon in ancient times: considerations of technical and ethical aspects," Water Supply, vol. 17, no. 5, pp. 1490-1498, 2017.

[2] H. Hatami and P. H. Gleick, "Conflicts over water in the myths, legends, and ancient history of the Middle East," Environment: Science and Policy for Sustainable Development, vol. 36, no. 3, pp. 10-11, 1994.

[3] A. Janku, "China: a hydrological history," Nature, vol. 536, no. 7614, pp. 28-29, 2016.

[4] D. K. Kreamer, "The past, present, and future of water conflict and international security," Journal of Contemporary Water Research \& Education, vol. 149, no. 1, pp. 87-95, 2012.

[5] R. Meinzen-Dick and M. Bakker, "Water rights and multiple water uses-framework and application to Kirindi Oya irrigation system Sri Lanka," Irrigation and Drainage Systems, vol. 15, no. 2, pp. 129-148, 2001.

[6] F. Molle, P. Jayakody, R. Ariyaratne, and H. S. Somatilake, "Irrigation versus hydropower: sectoral conflicts in southern Sri Lanka," Water Policy, vol. 10, no. S1, pp. 37-50, 2008.

[7] K. Nandalal and S. Simonovic, "Resolving conflicts in water sharing: a systemic approach," Water Resources Research, vol. 39, pp. 1-11, 2003.

[8] M. Samad, "Water institutional reforms in Sri Lanka," Water Policy, vol. 7, no. 1, pp. 125-140, 2005.

[9] M. G. Ghebrezgabher, T. Yang, and X. Yang, "Long-term trend of climate change and drought assessment in the horn of africa," Advances in Meteorology, vol. 2016, Article ID 8057641, 12 pages, 2016.

[10] J. Vido, P. Nalevanková, J. Valach, Z. Šustek, and T. Tadesse, "Drought analyses of the horné požitavie region (Slovakia) in the period 1966-2013," Advances in Meteorology, vol. 2019, Article ID 3576285, 10 pages, 2019.

[11] B. Khaniya, I. Jayanayaka, P. Jayasanka, and U. Rathnayake, "Rainfall trend analysis in Uma Oya basin, Sri Lanka, and future water scarcity problems in perspective of climate variability," Advances in Meteorology, vol. 2019, Article ID 3636158, 10 pages, 2019.

[12] D. Kum, K. J. Lim, C. H. Jang et al., "Projecting future climate change scenarios using three bias-correction methods," Advances in Meteorology, vol. 2014, Article ID 704151, 12 pages, 2014.

[13] W. Mo, H. Wang, and J. M. Jacobs, "Understanding the influence of climate change on the embodied energy of water supply," Water Research, vol. 95, pp. 220-229, 2016.

[14] M. Kleidorfer, M. Möderl, R. Sitzenfrei, C. Urich, and W. Rauch, "A case independent approach on the impact of climate change effects on combined sewer system performance," Water Science and Technology, vol. 60, no. 6, pp. 1555-1564, 2009.

[15] W. Wang, M. W. Ertsen, M. D. Svoboda, and M. Hafeez, "Propagation of drought: from meteorological drought to agricultural and hydrological drought," Advances in Meteorology, vol. 2016, Article ID 6547209, 5 pages, 2016.

[16] B. Kichonge, "The status and future prospects of hydropower for sustainable water and energy development in Tanzania," 
Journal of Renewable Energy, vol. 2018, Article ID 6570358, 12 pages, 2018.

[17] D. Jaroszweski, L. Chapman, and J. Petts, "Assessing the potential impact of climate change on transportation: the need for an interdisciplinary approach," Journal of Transport Geography, vol. 18, no. 2, pp. 331-335, 2010.

[18] R. García-Herrera, J. Díaz, R. M. Trigo, J. Luterbacher, and E. M. Fischer, "A review of the European summer heat wave of 2003," Critical Reviews in Environmental Science and Technology, vol. 40, no. 4, pp. 267-306, 2010.

[19] G. A. Meehl and C. Tebaldi, "More intense, more frequent, and longer lasting heat waves in the $21^{\text {st }}$ century," Science, vol. 305, no. 5686, pp. 994-997, 2004.

[20] C. Schär, P. L. Vidale, D. Lüthi et al., "The role of increasing temperature variability in European summer heatwaves," Nature, vol. 427, no. 6972, pp. 332-336, 2004.

[21] U. Shakoor, A. Saboor, I. Ali, and A. Q. Mohsin, "Impact of climate change on agriculture: empirical evidence from arid region," Pakistan Journal of Agricultural Sciences, vol. 48, no. 4, pp. 327-333, 2011.

[22] P. K. Jha, E. Xanthakis, S. Chevallier, V. Jury, and A. Le-Bail, "Assessment of freeze damage in fruits and vegetables," Food Research International, vol. 121, pp. 479-496, 2019.

[23] D. B. Lobell, A. Torney, and C. B. Field, "Climate extremes in California agriculture," Climatic Change, vol. 109, no. S1, pp. 355-363, 2011.

[24] Y. Fukushima, "A model of river flow forecasting for a small forested mountain catchment," Hydrological Processes, vol. 2, no. 2, pp. 167-185, 1988.

[25] M. G. Kang, J. H. Lee, and K. W. Park, "Parameter regionalization of a tank model for simulating runoffs from ungauged watersheds," Journal of Korea Water Resources Association, vol. 46, no. 5, pp. 519-530, 2013.

[26] K. Mizumura, "Runoff prediction by simple tank model using recession curves," Journal of Hydraulic Engineering, vol. 121, no. 11, pp. 812-818, 1995.

[27] P.-S. Yu and T.-C. Yang, "Using synthetic flow duration curves for rainfall-runoff model calibration at ungauged sites," Hydrological Processes, vol. 14, no. 1, pp. 117-133, 2000.

[28] D. Che and L. W. Mays, "Development of an optimization/ simulation model for real-time flood-control operation of river-reservoirs systems," Water Resources Management, vol. 29, no. 11, pp. 3987-4005, 2015.

[29] T. Haktanir and H. Ozmen, "Comparison of hydraulic and hydrologic routing on three long reservoirs," Journal of $\mathrm{Hy}$ draulic Engineering, vol. 123, no. 2, pp. 153-156, 1997.

[30] K. P. Singh and A. Snorrason, "Sensitivity of outflow peaks and flood stages to the selection of dam breach parameters and simulation models," Journal of Hydrology, vol. 68, no. 1-4, pp. 295-310, 1984.

[31] B. G. Tassew, M. A. Belete, and K. Miegel, "Application of HEC-HMS model for flow simulation in the lake tana basin: the case of gilgel abay catchment, upper blue nile basin, Ethiopia," Hydrology, vol. 6, no. 1, p. 21, 2019.

[32] S.-C. Yang and T.-H. Yang, "Uncertainty assessment: reservoir inflow forecasting with ensemble precipitation forecasts and HEC-HMS," Advances in Meteorology, vol. 2014, Article ID 581756, 11 pages, 2014.

[33] J. Adamowski, K. Adamowski, and A. Prokoph, "A spectral analysis based methodology to detect climatological influences on daily urban water demand," Mathematical Geosciences, vol. 45, no. 1, pp. 49-68, 2012.
[34] M. A. Gad, "A useful automated rainfall-runoff model for engineering applications in semi-arid regions," Computers \& Geosciences, vol. 52, pp. 443-452, 2013.

[35] M. Paudel, E. J. Nelson, C. W. Downer, and R. Hotchkiss, "Comparing the capability of distributed and lumped hydrologic models for analyzing the effects of land use change," Journal of Hydroinformatics, vol. 13, no. 3, pp. 461-473, 2010.

[36] A. K. Verma, M. K. Jha, and R. K. Mahana, "Evaluation of HEC-HMS and WEPP for simulating watershed runoff using remote sensing and geographical information system," Paddy and Water Environment, vol. 8, no. 2, pp. 131-144, 2009.

[37] M. U. Kale, M. B. Nagdeve, and S. B. Wadatkar, "Reservoir inflow forecasting using artificial neural network," Hydrology Journal, vol. 35, no. land2, p. 52, 2012.

[38] F. Othman and M. Naseri, "Reservoir inflow forecasting using artificial neural network," International Journal of the Physical Sciences, vol. 6, no. 3, pp. 434-440, 2011.

[39] A. Sedki, D. Ouazar, and E. El Mazoudi, "Evolving neural network using real coded genetic algorithm for daily rainfallrunoff forecasting," Expert Systems with Applications, vol. 36, no. 3, pp. 4523-4527, 2009.

[40] L. Burke, "Clustering characterization of adaptive resonance," Neural Networks, vol. 4, no. 4, pp. 485-491, 1991.

[41] O. R. Dolling and E. A. Varas, "Artificial neural networks for streamflow prediction," Journal of Hydraulic Research, vol. 40, no. 5, pp. 547-554, 2002.

[42] C. Zealand, D. Burn, and S. Simonovic, "Short term streamflow forecasting using artificial neural networks," Journal of Hydrology, vol. 214, no. 1-4, pp. 32-48, 1999.

[43] O. Oyebode and J. Adeyemo, "Reservoir inflow forecasting using differential evolution trained neural networks," in EVOLVE-A Bridge between Probability, Set Oriented Numerics, and Evolutionary Computation V, A. A. Tantar, E. Tantar, J.-Q. Sun et al., Eds., Springer, Cham, Switzerland, 2014.

[44] E. Sharghi, V. Nourani, H. Najafi, and A. Molajou, "Emotional ANN (EANN) and wavelet-ANN (WANN) approaches for markovian and seasonal based modeling of rainfall-runoff process," Water Resources Management, vol. 32, pp. 34413456, 2018.

[45] C. Bennett, R. A. Stewart, and C. D. Beal, "ANN-based residential water end-use demand forecasting model," Expert Systems with Applications, vol. 40, no. 4, pp. 1014-1023, 2013.

[46] B. Cannas, A. Fanni, L. See, and G. Sias, "Data preprocessing for river flow forecasting using neural networks: wavelet transforms and data partitioning," Physics and Chemistry of the Earth, Parts $A / B / C$, vol. 31, no. 18, pp. 1164-1171, 2006.

[47] T. Partal and Ö. Kişi, "Wavelet and neuro-fuzzy conjunction model for precipitation forecasting," Journal of Hydrology, vol. 342, no. 1-2, pp. 199-212, 2007.

[48] S. Kumar, M. K. Tiwari, C. Chatterjee, and A. Mishra, "Reservoir inflow forecasting using ensemble models based on neural networks, wavelet analysis and bootstrap method," Water Resources Management, vol. 29, no. 13, pp. 4863-4883, 2015.

[49] P. Coulibaly, F. Anctil, and B. Bobée, "Multivariate reservoir inflow forecasting using temporal neural networks," Journal of Hydrologic Engineering, vol. 6, no. 5, pp. 367-376, 2001.

[50] S. Debbarma and P. Choudhury, "River flow prediction with memory-based artificial neural networks: a case study of the Dholai river basin," International Journal of Advanced Intelligence Paradigms, vol. 15, no. 1, pp. 51-62, 2020. 
[51] H. M. Ibrahim, "Prediction of darbandikhan reservoir inflow using ANFIS models," Journal of Zankoy Sulaimani-Part A, vol. 19, no. 2, pp. 127-142, 2017.

[52] S. K. Jain, A. Das, and D. K. Srivastava, "Application of ANN for reservoir inflow prediction and operation," Journal of Water Resources Planning and Management, vol. 125, no. 5, pp. 263-271, 1999.

[53] R. B. Magar and V. Jothiprakash, "Intermittent reservoir daily-inflow prediction using lumped and distributed data multi-linear regression models," Journal of Earth System Science, vol. 120, no. 6, pp. 1067-1084, 2011.

[54] A. Moradi, A. Dariane, G. Yang, and P. Block, "Long-range reservoir inflow forecasts using large-scale climate predictors," International Journal of Climatology, vol. 40, no. 13, 2020.

[55] Ö. Kişi, "Streamflow forecasting using different artificial neural network algorithms," Journal of Hydrologic Engineering, vol. 12, no. 5, pp. 532-539, 2007.

[56] N. Basnayake, D. Attygalle, L. Liyanage, and K. Nandalal, "Ensemble forecast for monthly reservoir inflow; a dynamic neural network approach," in Proceedings of the 4th Annual International Conference on Operations Research and Statistics (ORS 2016), pp. 1-8, Singapore, January 2016.

[57] N. Basnayake, L. Liyanage, D. Attygalle, and K. Nandalal, "Effective water management in the mahaweli reservoir system; analyzing the inflow of the upmost reservoir," in Proceedings of the International Symposium for Next Generation Infrastructure; MART Infrastructure Facility, pp. 1-6, Wollongong, Australia, October 2013.

[58] Department of Census and Statistics, Paddy Statistics, http://www. statistics.gov.lk/agriculture/Paddy\%20Statistics/PaddyStats.htm, 2020.

[59] S. Arumugum, Water Resources of Ceylon its Utilization and Development, Water Resources Board, Sri Lanka, Colombo, Sri Lanka, 1st edition, 1969.

[60] NPC, Sri Lanka Status Report of Iranamadu Tank as of 28.01.2019, https://np.gov.lk/status-report-of-iranamadu-tank-as-of-28-01-2019/, Northern Provincial Council, Vavuniya, Sri Lanka, 2019, https://np. gov.lk/status-report-of-iranamadu-tank-as-of-28-01-2019/.

[61] J. Christensen, F. Boberg, O. Christensen, and P. LucasPicher, "On the need for bias correction of regional climate change projections of temperature and precipitation," Geophysical Research Letters, vol. 35, pp. 1-6, 2008.

[62] C. Teutschbein and J. Seibert, "Bias correction of regional climate model simulations for hydrological climate-change impact studies: review and evaluation of different methods," Journal of Hydrology, vol. 456-457, pp. 12-29, 2012.

[63] O. Varis, T. Kajander, and R. Lemmelä, "Climate and water: from climate models to water resources management and vice versa," Climatic Change, vol. 66, no. 3, pp. 321-344, 2004.

[64] W. Cabos, D. V. Sein, A. Durán-Quesada et al., "Dynamical downscaling of historical climate over CORDEX Central America domain with a regionally coupled atmosphere-ocean model," Climate Dynamics, vol. 52, no. 7-8, pp. 4305-4328, 2018.

[65] V. P. Pandey, S. Dhaubanjar, L. Bharati, and B. R. Thapa, "Hydrological response of Chamelia watershed in Mahakali Basin to climate change," Science of The Total Environment, vol. 650, pp. 365-383, 2019.

[66] D. Jacob, "A note to the simulation of the annual and interannual variability of the water budget over the Baltic Sea drainage basin," Meteorology and Atmospheric Physics, vol. 77, no. 1-4, pp. 61-73, 2001.

[67] D. Jacob, B. J. J. M. Van den Hurk, U. Andræ et al., “A comprehensive model inter-comparison study investigating the water budget during the BALTEX-PIDCAP period,"
Meteorology and Atmospheric Physics, vol. 77, no. 1-4, pp. 19-43, 2001.

[68] M. T. Hagan and M. B. Menhaj, "Training feedforward networks with the Marquardt algorithm," IEEE Transactions on Neural Networks, vol. 5, no. 6, pp. 989-993, 1994.

[69] S. Singh, S. Jain, and A. Bárdossy, "Training of artificial neural networks using information-rich data," Hydrology, vol. 1, no. 1, pp. 40-62, 2014.

[70] J. Wang, P. Shi, P. Jiang et al., "Application of BP neural network algorithm in traditional hydrological model for flood forecasting," Water, vol. 9, no. 1, pp. 48-63, 2017.

[71] A. Perera, H. Azamathulla, and U. Rathnayake, "Comparison of different artificial neural network (ANN) training algorithms to predict atmospheric temperature in Tabuk, Saudi Arabia," MAUSAM: Quarterly Journal of Meteorology, Hydrology \& Geophysics, vol. 71, no. 2, pp. 551-560, 2020.

[72] APHRODITE's Water Resources, https://www.chikyu.ac.jp/ precip/english/?fbclid=IwAR0B13K0v2eaZpwdvIKItjmhbo5f z0_-EXOJ5ZnENbzhrXq015xNciZFjHU, 2020.

[73] A. Yatagai, K. Kamiguchi, O. Arakawa, A. Hamada, N. Yasutomi, and A. Kitoh, "APHRODITE: constructing a long-term daily gridded precipitation dataset for asia based on a dense network of rain gauges," Bulletin of the American Meteorological Society, vol. 93, no. 9, pp. 14011415, 2012.

[74] IPCC, "Climate change 2014: synthesis report," in Fifth Assessment Report of the Intergovernmental Panel on Climate Change, R. K. Pachauri and L. A. Meyer, Eds., pp. 1-151, Intergovernmental Panel on Climate Change, Geneva, Switzerland, 2014.

[75] D. P. Van Vuuren, J. Edmonds, M. Kainuma et al., "The representative concentration pathways: an overview," Climatic Change, vol. 109, no. 1-2, pp. 5-31, 2011.

[76] G. Lenderink, A. Buishand, and W. van Deursen, "Estimates of future discharges of the river Rhine using two scenario methodologies: direct versus delta approach," Hydrology and Earth System Sciences, vol. 11, no. 3, pp. 1145-1159, 2007.

[77] U. Ghimire, G. Srinivasan, and A. Agarwal, "Assessment of rainfall bias correction techniques for improved hydrological simulation," International Journal of Climatology, vol. 39, no. 4, pp. 2386-2399, 2018.

[78] P. Stanzel and H. Kling, "From ENSEMBLES to CORDEX: evolving climate change projections for upper Danube river flow," Journal of Hydrology, vol. 563, pp. 987-999, 2018.

[79] A. B. Dariane and S. Azimi, "Streamflow forecasting by combining neural networks and fuzzy models using advanced methods of input variable selection," Journal of Hydroinformatics, vol. 20, no. 2, pp. 520-532, 2017.

[80] S. Nacar, M. A. Hinıs, and M. Kankal, "Forecasting daily streamflow discharges using various neural network models and training algorithms," KSCE Journal of Civil Engineering, vol. 22, no. 9, pp. 3676-3685, 2017.

[81] T. Peng, J. Zhou, C. Zhang, and W. Fu, "Streamflow forecasting using empirical wavelet transform and artificial neural networks," Water, vol. 9, no. 6, pp. 1-20, 2017, 406.

[82] G. Uysal, A. A. lorman, and A. fensoy, "Streamflow forecasting using different neural network models with satellite data for a snow dominated region in Turkey," Procedia Engineering, vol. 154, pp. 1185-1192, 2016. 